\title{
DISSOLUTION INHIBITION MECHANISM OF POLYMERIC INHIBITOR IN A NOVOLAK RESIN MATRIX
}

\author{
YUKO TSUCHIYA, TOSHIO SAKAMIZU and HIROSHI SHIRAISHI \\ Central Research Laboratory, Hitachi Ltd., Kokubunji, Tokyo 185, Japan
}

\section{Introduction}

We have investigated a chemically amplified positive resist system that consisted of novolak resin, an acid generator and a polymeric dissolution inhibitor with an acid-labile group [1,2]. The polymeric dissolution inhibitor, tetrahydropyranyl-protected poly(p-vinylphenol) (THP-M) was found to be a more effective dissolution inhibitor than a molecular dissolution inhibitor, tetrahydropyranyl-protected bisphenol-A (THP-BA) in a novolak resin matrix [3]. In this paper, we describe the dissolution inhibition mechanism of the polymeric inhibitor in terms of the disruption of the hydrogen bonding network in the novolak matrix.

\section{Experimental}

The molecular structures of compounds used in this work are shown in Fig. 1. The novolak resin was supplied by Hitachi Chemical Co., and the THP-BA and THP-M were synthesized as described in the literature $[1,4]$. Bis(ter-butyl phenyl) iodonium triflate (TBIT) used as a photoacid generator was synthesized in our laboratory[4]. A commercially available polystyrene was used as the base matrix of a photo-acid generating film containing the photo-acid generator.

Inhibitor / novolak films were prepared by spincoating onto appropriate substrates. This was followed by baking on a hot-plate at $100^{\circ} \mathrm{C}$ for $5 \mathrm{~min}$. The dissolution rate of the inhibitor / novolak films was measured by developing the films in a developer (NMD-3, $2.38 \mathrm{wt} \%$, Tokyo Ohka Co.). Fourier transformation-infrared (FT-IR) spectra were measured with a Perkin Elmer 1720X FT-IR spectrometer.

The acid diffusion capability of the inhibitor / novolak films was evaluated by the modified method reported by Schlegel, et. al. [5], which is shown in Fig. 2. The inhibitor/ novolak film 


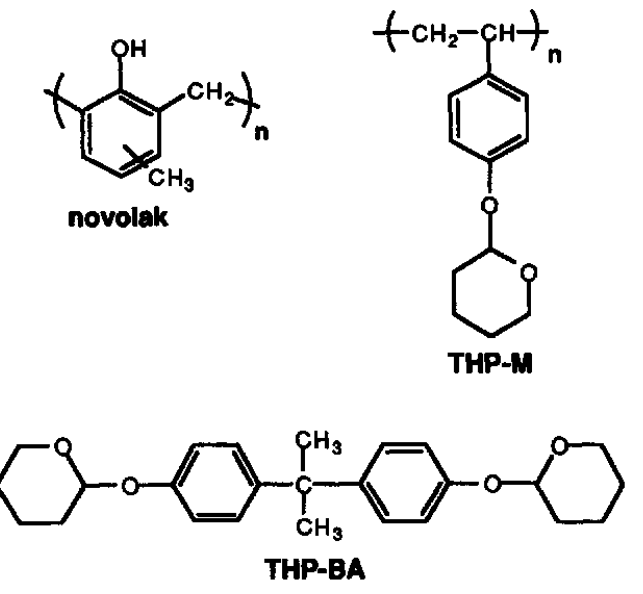

Fig. 1 Molecular structures of compounds used in this work.
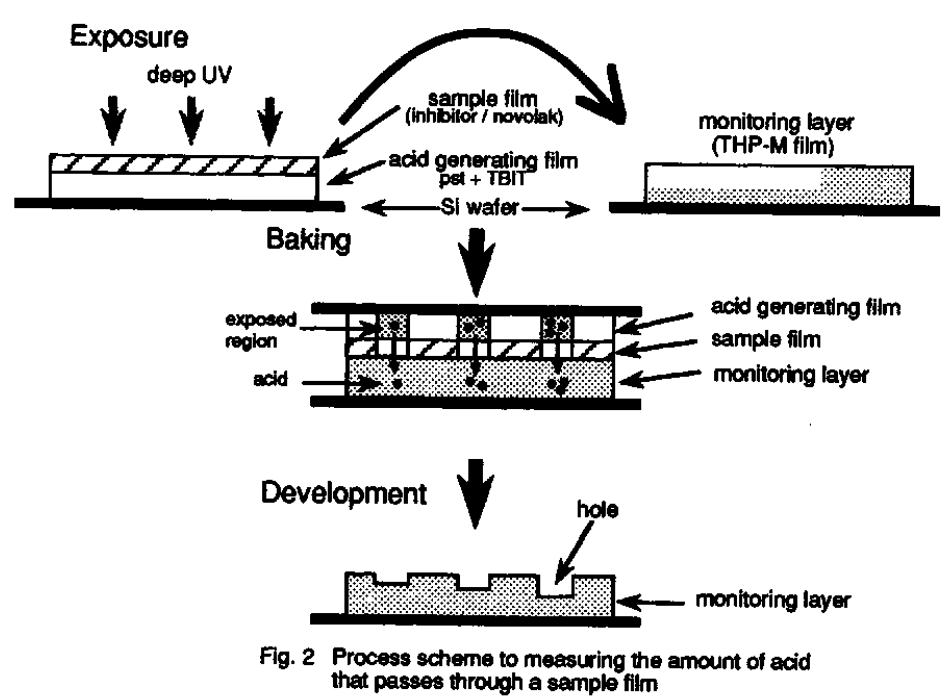

was spin-coated on a layer containing photo-acid generator which was pre-coated onto a Si wafer. Deep-UV exposure of the inhibitor / novolak film was made with a $\mathrm{Hg}$-Xe lamp using an interference filter $(250 \mathrm{~nm})$. After deep-UV exposure, the inhibitor / novolak film was put on a THP-M film used as a monitoring layer and again baked on a hot-plate. The THP-M film was developed in a developer for $2 \mathrm{~min}$, then the hole depth of the THP-M film, which is proportional to the amount of acid diffused from the inhibitor / novolak film, was measured with an Alphastep 200 profilometer (Tencor Instr.).

\section{Results and Discussion}

The dissolution inhibition capabilities of THP-M and THP-BA in a novolak resin matrix are shown in Fig. 3, where the dissolution rate of the inhibitor / novolak films in the developer is plotted as a function of the inhibitor content. As can be seen, the dissolution inhibition

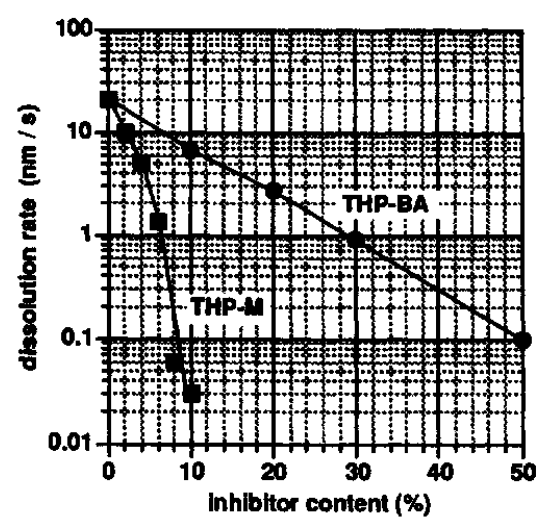
capability of THP-M is stronger than that of THP-BA. Fig. 3 Dissolution rate of the inhibitor/ novolak mixture as a The THP-M and THP-BA both have the same acid-labile groups, and since each mixture matrix has the same inhibitor content, each mixture film should contain nearly the same molar of THP groups. Therefore, we attribute the higher dissolution inhibition capability of THP-M to the "polymeric structure". 
The FT-IR spectra of the inhibitor / novolak films are shown in Fig. 4. Both THP-inhibitor / novolak systems show the blue-shift of the phenolic $\mathrm{O}-\mathrm{H}$ stretching band, which indicates disruption of the hydrogen bonding network in the novolak resin matrix. The degree of blue-shift in the THP-M / novolak mixture is greater by $9 \mathrm{~cm}^{-1}$ than that in the THP-BA / novolak film at the 50:50 mixing ratio, which shows that THP-M disrupts strongly the hydrogen bonding network in the novolak matrix. In a diazonaphthoquinone (DNQ) / novolak system, the blue-shift of the O$\mathrm{H}$ band is strongly correlated to the dissolution inhibition [6]. Therefore, we concluded that the THP-M also disrupts strongly the hydrogen bonding network in the novolak matrix, which causes the strong dissolution inhibition.

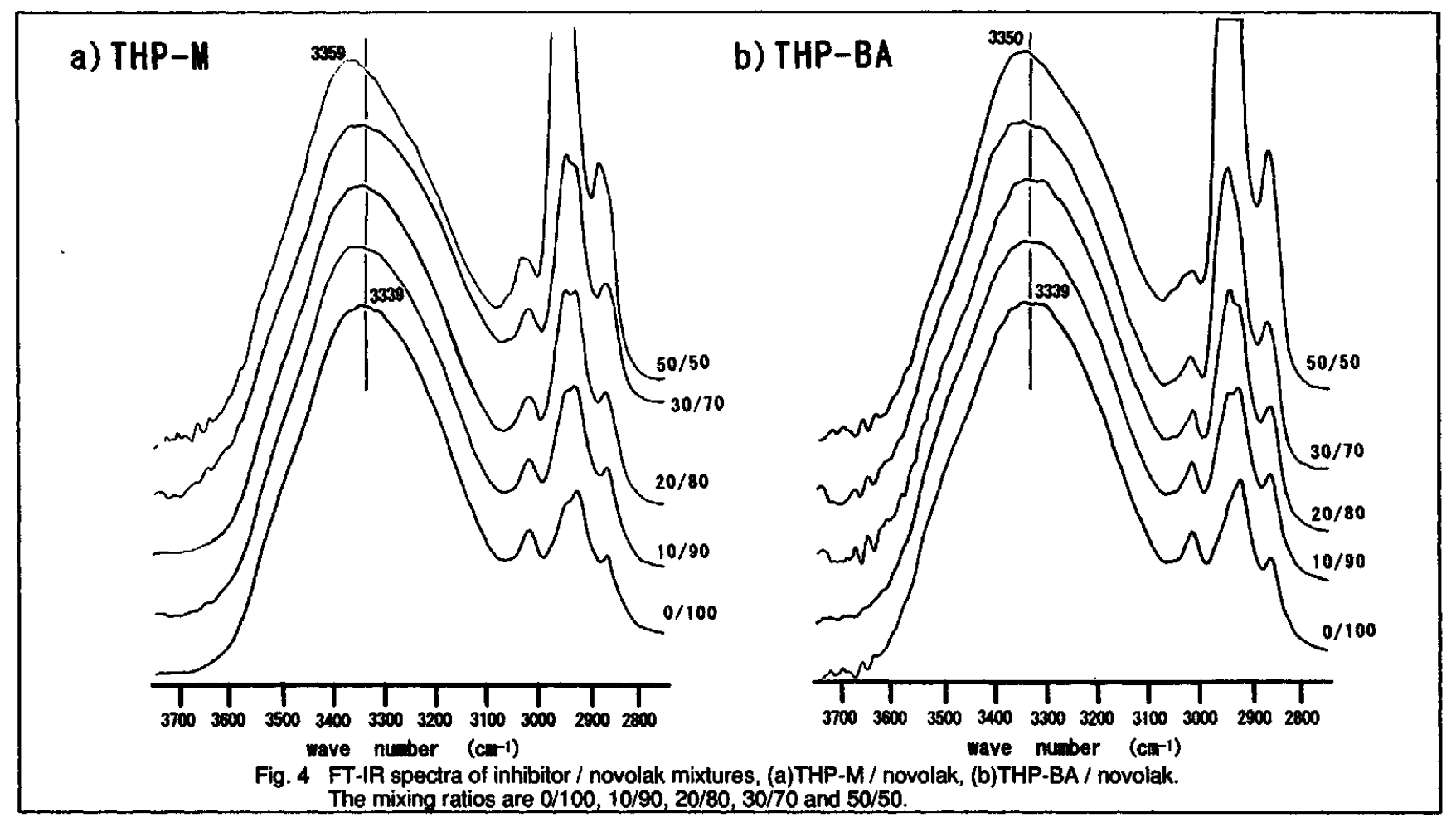

Recently, an acid diffusion mechanism was proposed by Yoshimura et.al. [7], in which the acid diffuses along "acid diffusion channels" formed by continuous active O-H groups and vacancies in the novolak resin matrix. It was also suggested that these acid diffusion channels are related to the " diffusion channel" described in the dissolution mechanism presented by Huang et. al [8]. If the inhibitors disrupt the hydrogen bonding network in the novolak matrix and block the diffusion channels, this would suppress the acid diffusion in the inhibitor / novolak matrix. We observed the acid diffusion abilities of the THP-inhibitor / novolak (10 / 90) matrices (Fig. 5). 
Both films that contained an inhibitor allowed less acid to pass through the film than the pure novolak film because of the acid consumption by deprotection reactions of THP groups. In Fig. 5, the amount of acid passed through the THP-M / novolak film is less than the THP-BA / novolak film. As the number of THP groups deprotected by photo-generated acids is nearly the same in each inhibitor / novolak matrix, the stronger

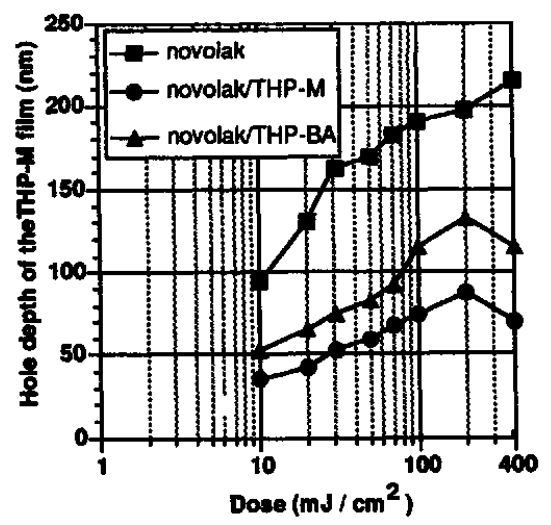

Fig. 5 Hole depth of the monitoring layer (THP-M) film as a function of exposure dose. PEB: $100 \mathrm{C} / 20 \mathrm{~min}$; Development: NMD-3 (2.38\%) $2 \mathrm{~min}$. dissolution inhibitor, THP-M, suppresses acid diffusion in the novolak resin matrix much more effectively than THP-BA.

\section{Conclusion}

The polymeric dissolution inhibitor, THP-M inhibits dissolution much more effectively than THP-BA. We found that both THP-inhibitor / novolak systems showed the blue-shift of the phenolic O-H stretching band, which indicated the disruption of the hydrogen bonding network in the novolak resin matrix. We also found that the acid diffusion was more suppressed in THP-M / novolak film than in THP-BA / novolak film.

\section{References}

[1] H. Shiraishi, N. Hayashi, T. Ueno, T. Sakamizu and F. Murai, J. Vac. Sci. Techonol. B9 (1991) 3343.

[2] T. Sakamizu, H. Yamaguchi, H. Shiraishi, F. Murai and T. Ueno, J. Vac. Sci. Techonol. B11 (1993) 2812.

[3] L. Schlegel, T. Ueno, H. Shiraishi, N. Hayashi, S. Hesp and T. Iwayanagi, Jpn. J. Appl. Phys. 28 (1989) 2114.

[4] S. A. M. Hesp, N. Hayashi and T. Ueno, J. Appl. Polym. Sci. 42 (1991) 877.

[5] L. Schlegel, T. Ueno, H. Shiraishi, N. Hayashi and T. Iwayanagi, J. Vac. Sci. Techonol. B9 (1991) 278.

[6] K. Honda, B. T. Beauchemin, Jr., R. J. Hurditch, A. J. Blakeney, Y. Kawabe and T. Kokubo Proc. SPIE 1262 (1990) 493

[7] T. Yoshimura, H. Shiraishi and S. Okazaki, Jpn. J. Appl. Phys. 34 (1995) 6786.

[8] J-P. Huang, T. K. Kwei and A. Reiser, Macromolecules 22 (1989) 4106. 